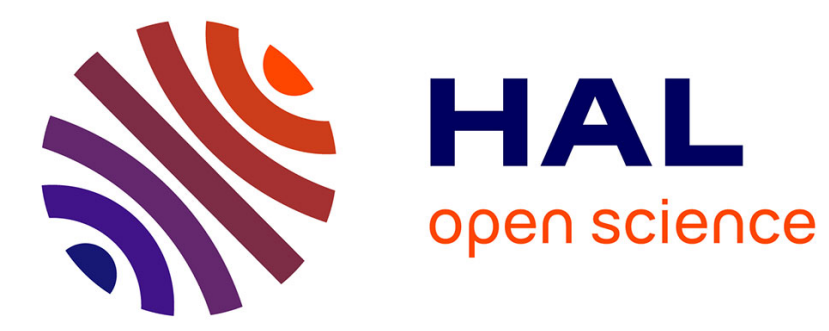

\title{
Correcting topography effects on terrestrial radar maps
}

\author{
Marion Jaud, R. Rouveure, P. Faure, M.O. Monod, L. Moiroux-Arvis
}

\section{To cite this version:}

Marion Jaud, R. Rouveure, P. Faure, M.O. Monod, L. Moiroux-Arvis. Correcting topography effects on terrestrial radar maps. IEEE International Radar Conference (RADAR), Oct 2014, Lille, France. 5 p. hal-01119030

\author{
HAL Id: hal-01119030 \\ https://hal.science/hal-01119030
}

Submitted on 20 Feb 2015

HAL is a multi-disciplinary open access archive for the deposit and dissemination of scientific research documents, whether they are published or not. The documents may come from teaching and research institutions in France or abroad, or from public or private research centers.
L'archive ouverte pluridisciplinaire HAL, est destinée au dépôt et à la diffusion de documents scientifiques de niveau recherche, publiés ou non, émanant des établissements d'enseignement et de recherche français ou étrangers, des laboratoires publics ou privés. 


\title{
Correcting topography effects on terrestrial radar
} maps

\author{
M. Jaud, R. Rouveure, P. Faure, M-O. Monod, L. Moiroux-Arvis \\ UR TSCF \\ Irstea, National Research Institute of Science and Technology for Environment and Agriculture \\ Aubière, France \\ marion.jaud@irstea.fr; raphael.rouveure@irstea.fr
}

\begin{abstract}
The vehicle-based radar named PELICAN has been used in a context of mobile mapping. R-SALM algorithm allows to simultaneously retrieve the trajectory of the vehicle and the map of the environment. This article proposes a method to correct the radar map distortions induced by local topographic effects. The a priori knowledge of the area topography is provided by a digital elevation model. An orthorectification process has been developed to correct the panoramic radar images. By applying the method to the data obtained on a course with large variations in altitude it was shown that the corrected panoramic radar images are contracted by the orthorectification process. An orthorectified map is then built by merging the panoramic images and finally the orthorectified trajectory is compared to the non-orthorectified trajectory.
\end{abstract}

\section{Keywords-FMCW radar; orthorectification; cartography}

\section{INTRODUCTION}

This study focuses on data provided by PELICAN radar [1]. The PELICAN radar is a terrestrial FMCW radar which can be loaded at the top of a vehicle. Thanks to its rotating antenna, the system provides maps of the surrounding environment. It appears that these maps can be distorted when the acquisition takes place in hilly terrain.

Most of the time, a map translates a three-dimensional environment to a two-dimensional picture. The aim of geocoding is to reconstruct the correct imaging geometry so as each image pixel is associated to its position on the earth. For each point of the environment, the sensor measures the radial line of sight distance to each target. This is the slant range distance. Hence, 2D representations of these data may be affected by distortions due to topographic effects. For this reason, the corresponding true horizontal distance (called ground range distance or planimetric distance) has to be calculated. "Orthorectification" is a procedure that removes distortions from the image, creating an "ortho-image" with features positioned as they would be in a planimetric map [2]. Without orthorectification, scale is not constant in the image and accurate measurements of distance are impossible. Generally speaking, an "ortho-image" refers to aerial photographs or satellite images. Nevertheless, the concept of orthorectification can be extended to any $2 \mathrm{D}$ remote sensing data in a 3D environment. Lot of papers tackle the question of distortions and terrain correction of radar images [3][4][5], usually concerning aerial SAR data. The situation is greatly different in our case. Indeed, our radar is approximately situated at the ground altitude and scans the environment in the horizontal plane. Thus the effects caused by the land topography are different from those found on aerial SAR images.

After a brief description of the PELICAN radar system and of the radar map building process, the article shows how the topography can affect the geometry of radar datasets. A method is proposed to correct these effects in order to "orthorectify" the datasets.

\section{RADAR MAP BUILDING}

The PELICAN radar can be easily loaded onto different mobile platforms (Fig. 1). This radar uses the Frequency Modulated Continuous Wave (FMCW) principle as described in details in [1] and [6]. The radar range is $100 \mathrm{~m}$ with a transmitted power about $50 \mathrm{~mW}$ (other technical characteristics of PELICAN radar are detailed in Table I). Waves are emitted through an antenna (aperture angle $20^{\circ}$ vertical, $5^{\circ}$ horizontal) rotating in horizontal plane, so that a strip of ground perpendicular to the vehicle displacement plane is illuminated.

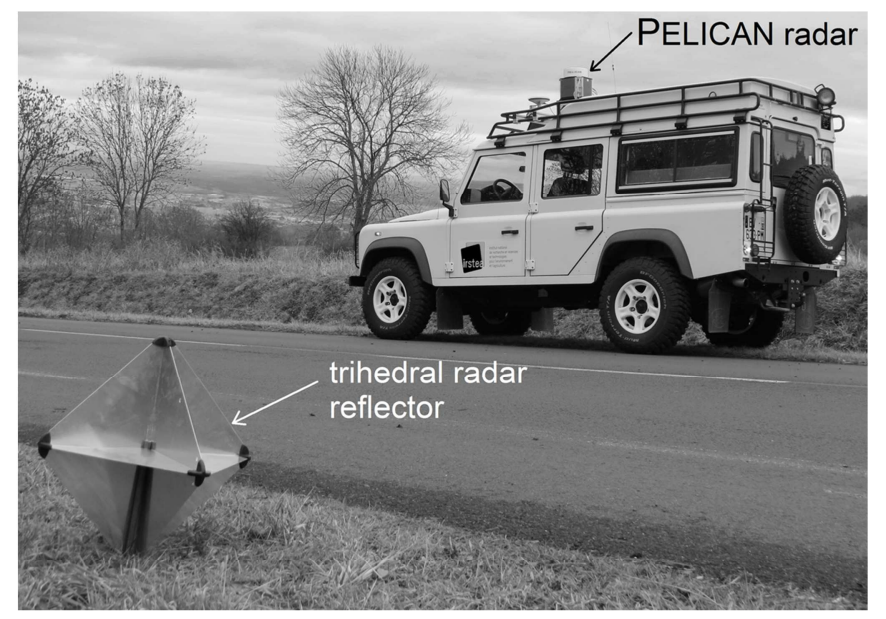

Fig. 1. PELICAN radar system loaded on an all-terrain vehicle. A trihedral reflector can be seen in the foreground. 
TABLE I. MAIN CHARACTERISTICS OF PELICAN RADAR

\begin{tabular}{|l|l|}
\hline Transmitted power & $50 \mathrm{~mW}$ \\
\hline Antenna gain & $20 \mathrm{~dB}$ \\
\hline Carrier frequency & $24 \mathrm{GHz}$ \\
\hline Range & $100 \mathrm{~m}$ \\
\hline Angular / Distance resolution ${ }^{\mathrm{a}}$ & $5^{\circ} / 1 \mathrm{~m}$ \\
\hline Accuracy (on canonical target) & $2 \mathrm{~cm}$ \\
\hline Size / Weight & $27 \times 24 \times 30 \mathrm{~cm} / 10 \mathrm{~kg}$ \\
\hline
\end{tabular}

A portion of the emitted wave is reflected back towards the radar antenna. Following the FMCW radar theory, the radar target distance is computed from the beat frequency [7]. The PELICAN radar achieves a complete scan in one second. An image is built up from the successive angular scans recorded during the antenna rotation.

A $360^{\circ}$ radar scan in the horizontal plane leads to a polar image built up from radar-target distances measured by FFT techniques at each step of antenna rotation in the horizontal plane. The distance and the angular resolution in the polar image are respectively about $1 \mathrm{~m}$ and $5^{\circ}$. At the end of a complete antenna scan, the intra-scan distortions due to vehicle motion during antenna rotation are corrected and the speckle is filtered. The 1025 x 1025 pixel image computed is called "panoramic radar image" (Fig. 2a).

The global map is built gradually by associating successive panoramic radar images thanks to the "R-SLAM algorithm" [1]. The global radar map is computed independently of the platform dynamics and of the radar position on the vehicle. For the $n^{\text {th }}$ panoramic radar image, this approach includes two major steps:

- Map matching (performing a 3D cross-correlation: two translations and one rotation) between the $\mathrm{n}^{\text {th }}$ radar scan and the previously constructed map. The maximum of the correlation matrix gives an estimate of the radar inter-scan displacement and of the rotation.

- Global map updating, merging the $\mathrm{n}^{\text {th }}$ panoramic radar image with the previously recorded map.

The global radar map is a gray-scale raster, with a spatial resolution of $20 \mathrm{~cm}$. Considering successive inter-scan displacements and rotations, the relative radar trajectory (named "R-SLAM trajectory") is computed simultaneously.

The global map is finally georeferenced either by taking advantage of GPS recording or by manual or automatic matching to an orthophotograph, as described in [8].

\section{EFFECTS OF THE TOPOGRAPHY ON THE IMAGE GEOMETRY}

Considering the scale of the study (from few hundred meters to few kilometers), the curved geometry of Earth's surface is not taken into account. Moreover, the inner distortions due to the sensor characteristics are not considered.

As mentioned in [5] and [9], the relief effects can be divided in two main categories:
- $\quad$ radiometric effects;

- geometric effects.

As reported in [5], rugged terrain changes the recorded brightness values due to changes in the local scattering area and changing scattering mechanisms due to different incident angle. In this paper, we focus on mapping applications without quantitative radiometric analysis, so radiometric terrain effects will not be detailed any more.
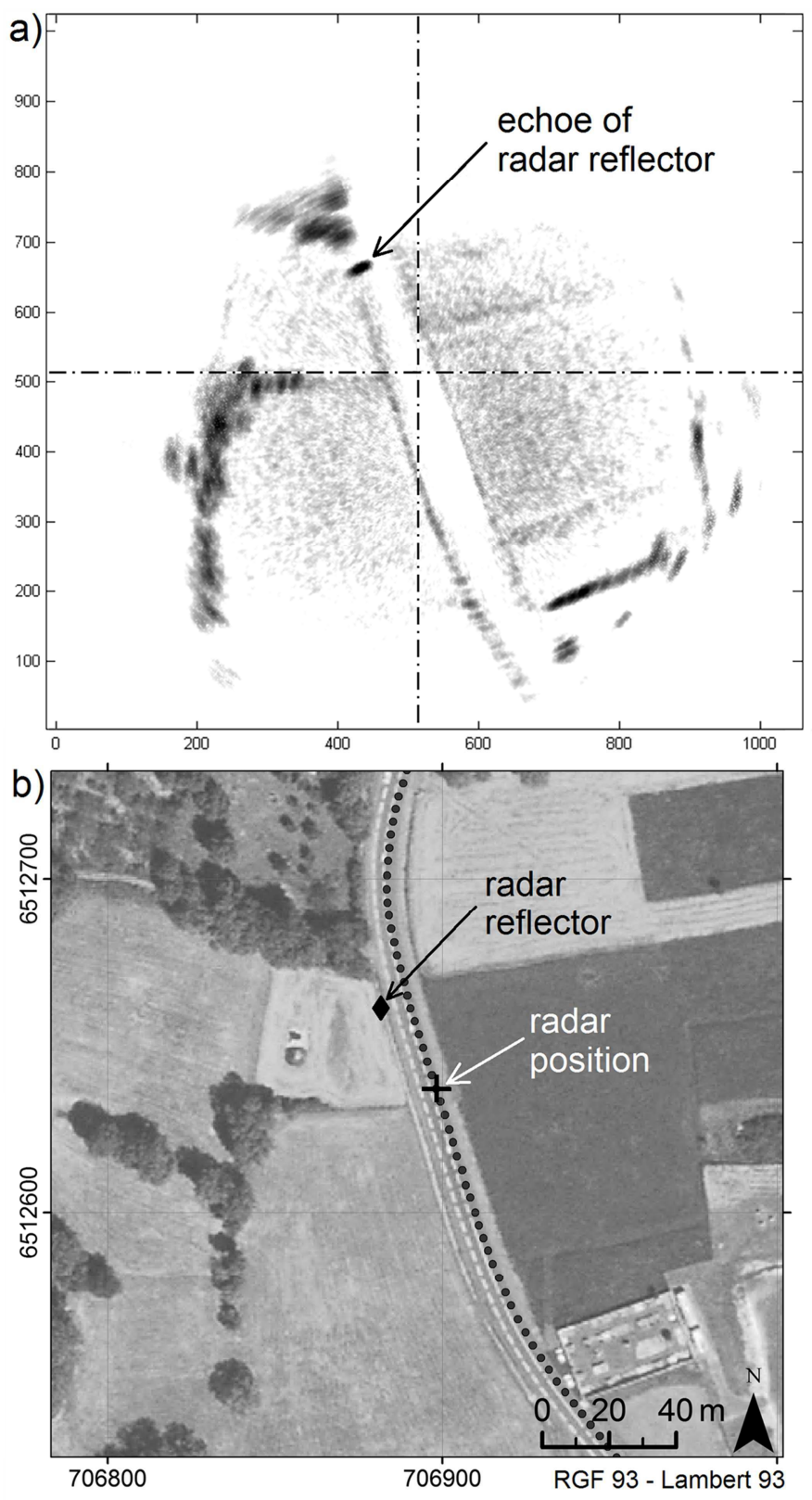

Fig. 2. (a) Example of a $100 \mathrm{~m}$ range panoramic radar image centered on the radar position and (b) the corresponding area on the RGB orthophotograph (BD ortho@ - IGN®).

As for satellite SAR images [9][10], precise terrain geocoding requires an a priori knowledge of the surrounding land topography and additional information about the platform 
displacement. In the case of PELICAN radar, geometric terrain effects have two main consequences on the radar data:

- the change in the radar ground coverage;

- the distortion of the map due to the difference between slant distance and the actual planimetric distance or ground range distance.

Regarding ground coverage, the change is particularly appreciable when the acquisition plane remains horizontal while the surrounding environment is sloped (Fig. 3a). In this configuration, the distance of the intersection of the radar beam with the ground is increased on the downhill side and decreased on the uphill side. The incidence angle is also modified. On the contrary, when the acquisition plane is parallel to the terrain slope, the ground coverage and the angle of incidence are quasi-similar to an acquisition on a flat area (Fig. 3b). Nevertheless, according to the path, different terrain configurations can appear at the same time depending on the observation direction.

\section{MODELLING AND CORRECTING DISTORTIONS OF THE RADAR MAP}

Each panoramic radar image is initially acquired as a slant range image, that is to say each target is located relatively to the radar position. It appears that the topographical variations affect the distance with which targets are displayed on a radar scan in a specified direction. On sloped ground, the slant range image is so affected by geometric distortions. Combining the panoramic images to build the global radar map, the deviations are added to one another and then they are very difficult to quantify. Indeed, as the vehicle moves forward, the line of sight of a given feature varies from one panoramic image to another. Therefore, each raw radar panoramic image must be corrected separately to create an "orthorectified panoramic image".

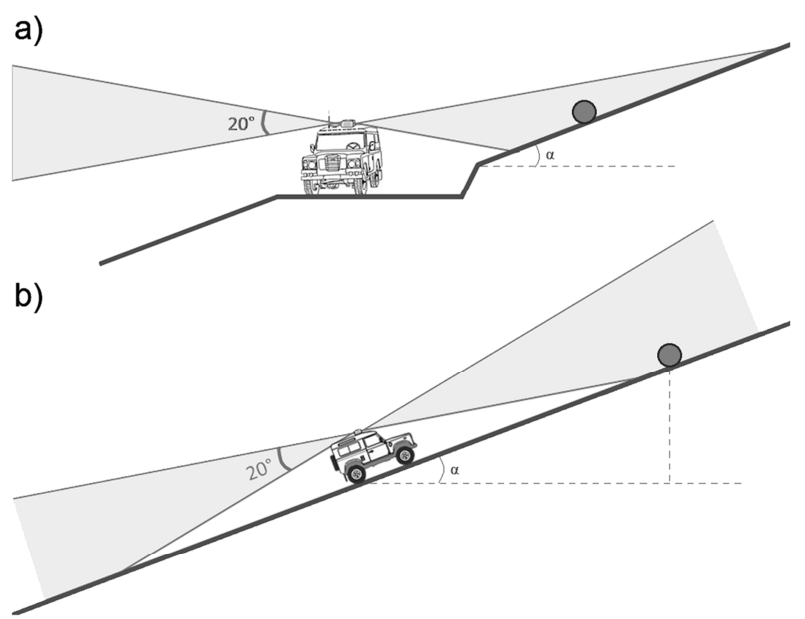

Fig. 3. Illustration of relief effects on the ground coverage of the radar beam.

A numerical model has been developed in Matlab® to show the distortions induced by the topography and to assess the efficiency of the orthorectification process. Simulations were performed with artificially computed reliefs and different arrangements of targets. The land topography leads to overvalue the measured slant range distance $\mathrm{D}$ in comparison with the ground range planimetric distance $\rho_{A}$ (Fig. 4).

Orthorectifying the panoramic radar images involves finding for each radar echo the corresponding position in realworld reference coordinates. In this study, a Digital Elevation Model (DEM) is supposed to be available. The radar panoramic image, centered on the radar position, is north reoriented, like the DEM. The rotation angle of the first panoramic image is deduced from the heading parameter of the mobile platform. This heading parameter is computed from the trajectory measured by the GPS receiver. The following panoramic images are oriented using the onboard gyrometer. $\mathrm{R}\left(\mathrm{X}_{\mathrm{R}}, \mathrm{Y}_{\mathrm{R}}, \mathrm{Z}_{\mathrm{R}}\right)$ is the radar position, measured by centimetric GPS. $A\left(x_{A}, y_{A}\right)$ is a pixel of the panoramic radar image. $\left(\mathrm{X}_{\mathrm{A}}, \mathrm{Y}_{\mathrm{A}}, \mathrm{Z}_{\mathrm{A}}\right)$ are the corresponding real-world coordinates. $\mathrm{D}$ refers to the slant range distance measured by the radar. The cell $\left(\mathrm{x}_{\mathrm{D}}, \mathrm{y}_{\mathrm{D}}\right)$ is the position in the raw panoramic image. The corresponding altitude $Z_{D E M}\left(\mathrm{x}_{\mathrm{D}}, \mathrm{y}_{\mathrm{D}}\right)$ is retrieved from the DEM. The corresponding planimetric distance $\rho_{\mathrm{A}}$ is provided by (1):

$$
\rho_{A}=\frac{D}{\sqrt{1+\left[\left(Z_{D E M}\left(x_{D}, y_{D}\right)-Z_{R}\right) / D\right]^{2}}}
$$

Thus, knowing the distance $\mathrm{D}$ to the radar position $\mathrm{R}$, the spatial resolution and the heading parameter, the real-world coordinates $\left(\mathrm{X}_{\mathrm{A}}, \mathrm{Y}_{\mathrm{A}}\right)$ may be deduced from $\rho_{\mathrm{A}}$.

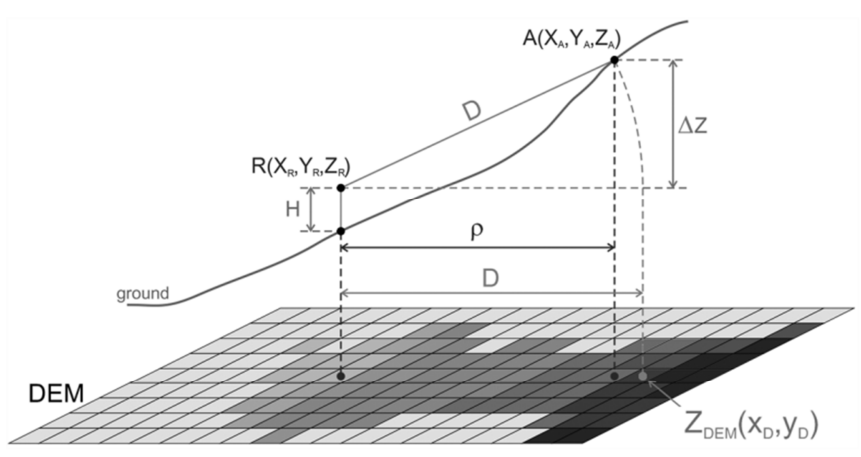

Fig. 4. Definition of the parameters used in the orthorectification process.

\section{GROUND-TRUTH VALIDATION}

This method was implemented on a dataset collected along a $2.5 \mathrm{~km}$ section of a sloping road with a difference in altitude of $160 \mathrm{~m}$, between Romagnat and Opme (Auvergne, France). Throughout the acquisition session, the radar position was measured by a ProFlex ${ }^{\circledR} 500$ GPS receiver at the rate of one position per second. After post-processing, the positioning accuracy is $1 \mathrm{~cm}$ horizontally and $1 \mathrm{~cm}$ vertically. The presented results have been georeferenced in RGF 93 Lambert 93, the French official coordinate system, based on GRS 80 ellipsoid. The DEM used in this study is an extract of the BD Alti®, an altimetric database provided by IGN (French National Geographic Institute). As its spatial resolution is 25 $\mathrm{m}$, the BD Alti ${ }^{\circledR}$ extract has been beforehand interpolated on an oversampled grid of one meter resolution. Metallic trihedral radar reflectors (Fig. 1) have been erected on the study area 
and georeferenced so as to assess the efficiency of the orthorectification.

Fig. 5 presents an example of the orthorectification process on a panoramic radar image. Fig. $5 \mathrm{c}$ is the differential between the raw panoramic radar image (Fig. 5a) and the orthorectified panoramic radar image (Fig. 5b). The black areas correspond to areas where radar echoes have been deleted during the orthorectification process. In opposite, the white areas correspond to the areas where these echoes appeared. It can be seen that the orthorectification process tends to contract the panoramic images. This shift can amount up to a displacement of several pixels in azimuth direction. Some areas of the panoramic radar image are not affected by the orthorectification process. Indeed, where the height differences are low, induced distortions are negligible. The effects of the orthorectification process can be quantified by using a georeferenced radar reflector.
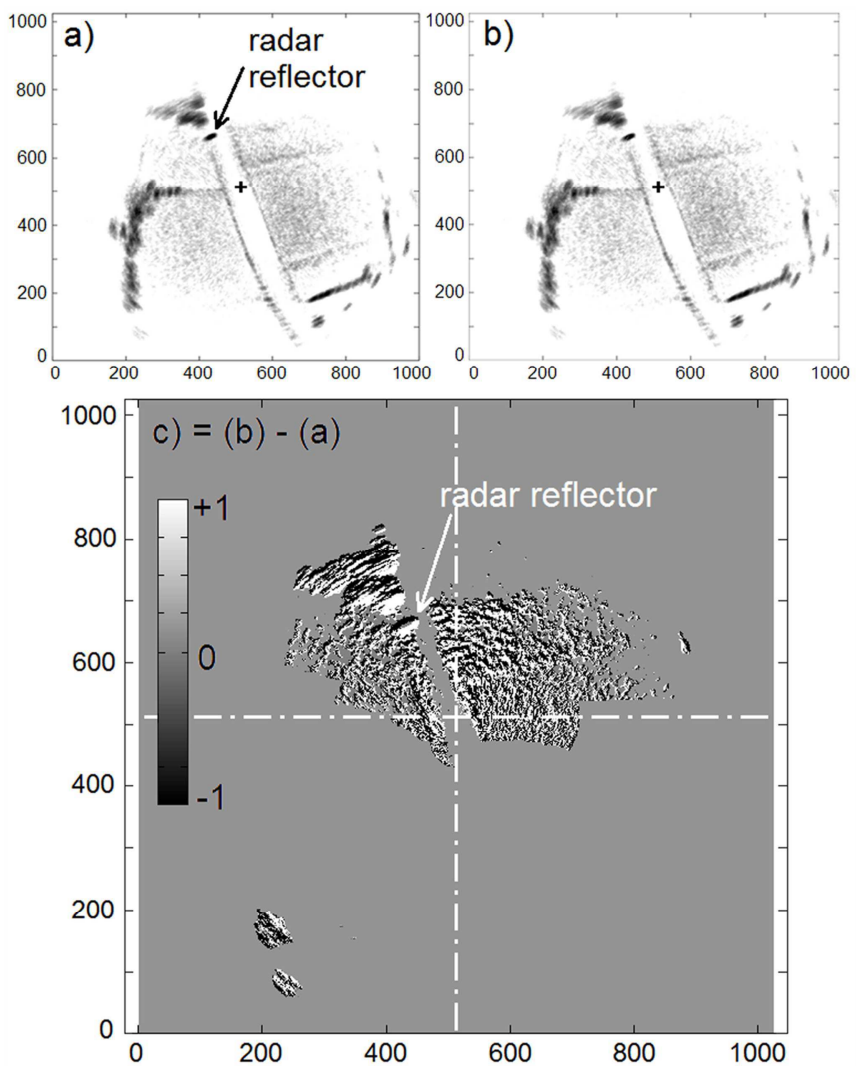

Fig. 5. Comparison of (a) a raw panoramic radar image and (b) an orthorectified panoramic radar image. The differential between (b) and (a) is presented in (c). The black areas correspond to areas where radar echoes have been deleted after the orthorectification. The white areas correspond to the areas where these echoes have appeared.

In the example depicted in Fig. 5, the radar reflector echo is shifted of $0.63 \mathrm{~m}$. A geographical position of the reflector can be estimated from its position on raw panoramic radar image and on orthorectified panoramic radar image. To ensure that orthorectification improves the image geocoding, the reflector's positions computed from panoramic images are compared with its position measured by GPS. Table II shows the results of this comparison. GPS position is the ground- truth reference. It can be seen that the positioning RMS error is lower on the orthorectified panoramic radar image $(0.31 \mathrm{~m}$ against $1.01 \mathrm{~m}$ on the raw panoramic image). Once all the panoramic radar images have been orthorectified, they are associated by the R-SLAM algorithm so as to build an orthorectified global radar map (Fig. 6).

TABLE II. QUANTIFICATION OF THE ORTHORECTIFICATION EFFECTS

\begin{tabular}{|l|l|l|}
\hline $\begin{array}{c}\text { GPS position of } \\
\text { the radar } \\
\text { reflector } \\
\text { (Lambert 93) }\end{array}$ & $\begin{array}{c}\text { Position of the radar } \\
\text { reflector on the raw } \\
\text { panoramic image } \\
\text { (Lambert 93) }\end{array}$ & $\begin{array}{c}\text { Position of the radar } \\
\text { reflector on the } \\
\text { orthorectified panoramic } \\
\text { image (Lambert 93) }\end{array}$ \\
\hline $\mathrm{X}: 706882.54 \mathrm{~m}$ & $\mathrm{X}: 706882.20 \mathrm{~m}$ & $\mathrm{X}: 706882.40 \mathrm{~m}$ \\
$\mathrm{Y}: 6512666.21 \mathrm{~m}$ & $\mathrm{Y}: 6512667.16 \mathrm{~m}$ & $\mathrm{Y}: 6512666.56 \mathrm{~m}$ \\
& $\mathrm{RMS}$ error $=1.01 \mathrm{~m}$ & $\mathrm{RMS}$ error $=0.31 \mathrm{~m}$ \\
\hline
\end{tabular}

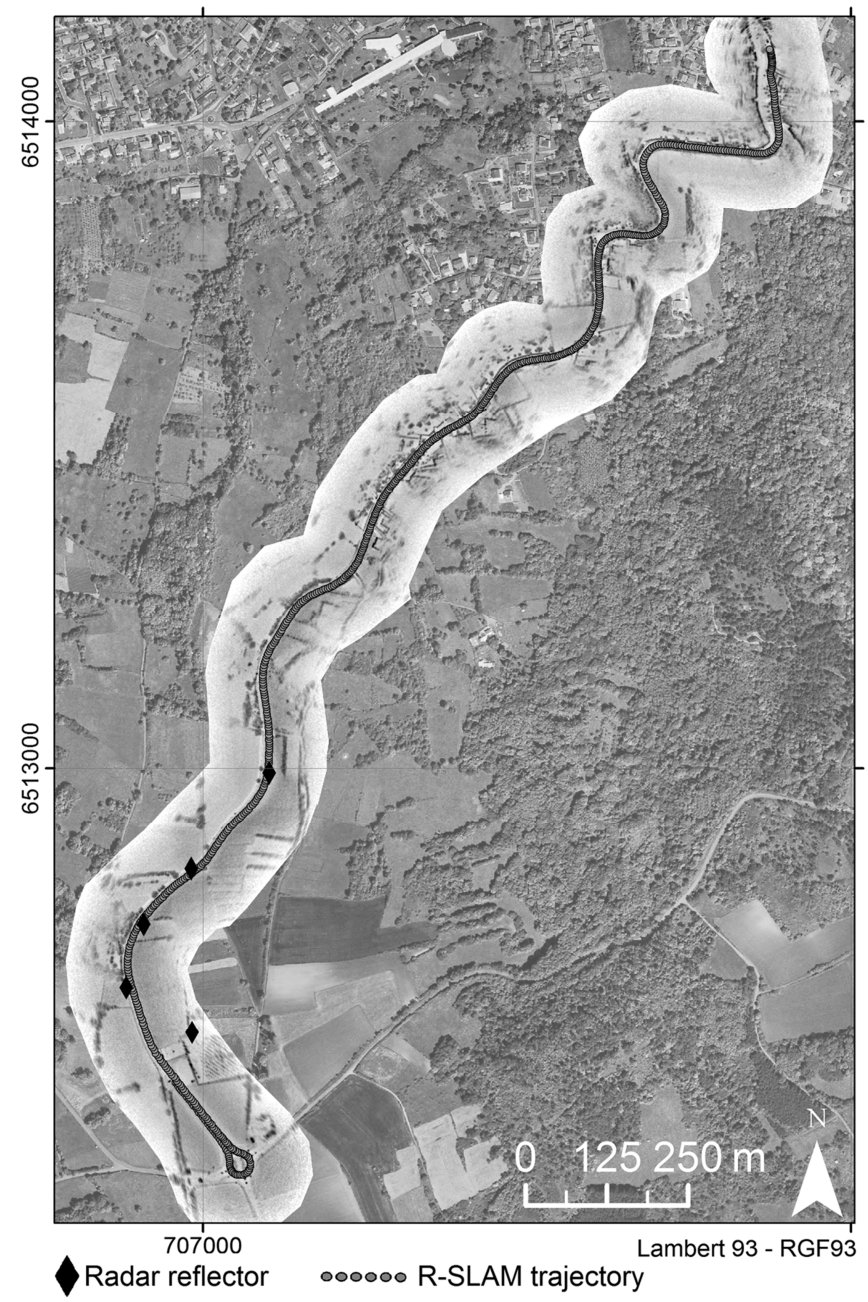

Fig. 6. Global orthorectified radar map along a $2.5 \mathrm{~km}$ section of a sloping road, between Romagnat and Opme (Auvergne, France). Along the path, the difference in altitude is about $160 \mathrm{~m}$.

As the panoramic radar images have been contracted, the global radar map and the R-SLAM trajectory (see section II) are also contracted by the orthorectification process. At this 
point, the "raw R-SLAM trajectory" (computed from nonorthorectified panoramic images) must be distinguished from the "orthorectified R-SLAM trajectory" (computed from orthorectified panoramic images). The comparison between the orthorectified and the raw R-SLAM trajectories shows a gap in the computed positions. Fig. 7a shows the unsigned value of this gap along the trajectory. This gap increases gradually along the trajectory and errors accumulate. At the end of the $2.5 \mathrm{~km}$ route, the gap is $9.6 \mathrm{~m}$ (Fig. 7a). Without orthorectification, the error on the R-SLAM trajectory increases as long as the road slopes upwards or downwards. Fig. $7 \mathrm{~b}$ depicts the longitudinal elevation profile of the road (measured by the on-boarded GPS receiver). The values of the gap between the orthorectified R-SLAM trajectory and the raw R-SLAM trajectory are correlated with the slope of the road.
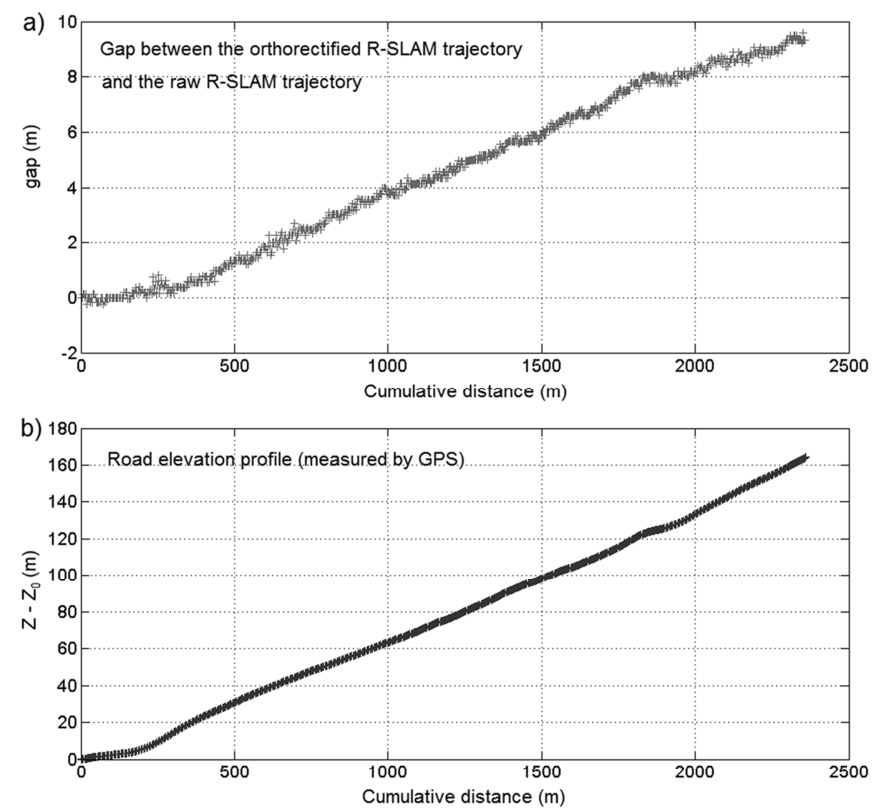

Fig. 7. (a) Gaps between the orthorectified R-SLAM trajectory and the raw R-SLAM trajectory along the route. (b) Relative longitudinal elevation profile of the road measured by the on-boarded GPS receiver.

\section{CONCLUSION}

Topographical variations induce a gap between the measured slant range distance and the planimetric distance. In cartographic applications, this gap must be corrected.
Considering the radar position in a DEM, it is possible to retrieve the difference of altitude between the radar position and every point of the environment scanned during the rotation of the antenna. Planimetric distances are thus computed and each panoramic radar image can be orthorectified. By improving the quality of the georeferencing, the orthorectification process improves the accuracy of the global radar map, and therefore that of the R-SLAM trajectory.

\section{ACKNOWLEDGMENT}

This work is part of PELICAN Project No. ANR-2010EMMA-033 supported by the Agence Nationale de la Recherche. The Project was labeled by ViaMeca French pole of competitiveness.

\section{REFERENCES}

[1] R. Rouveure, M-O. Monod, and P. Faure, "Mapping of the environment with a high resolution ground-based radar imager", IEEE International Conference on Radar Systems RADAR'09, pp.822-828, 2009.

[2] K. Novak, "Rectification of digital imagery", Photogrammetric engineering and remote sensing, vol. 58, pp. 339-344, 1992.

[3] H. Rantakokko, and D. Rosenholm, "Rectification of Slant Range Imagery Through a Direct Image to Ground Relationship", The Photogrammetric Record, vol. 16, pp. 685-694, October 1999.

[4] H. Liu, Z. Zhao, and K.C. Jezek, "Correction of positional errors and geometric distortions in topographic maps and DEMs using rigorous SAR simulation technique", Photogrammetric engineering and remote sensing, vol. 70, pp. 1031-1042, 2004.

[5] A. Loew, and W. Mauser, "Generation of geometrically and radiometrically terrain corrected SAR image products", Remote Sensing of Environment, vol. 106, pp. 337-349, February 2007.

[6] M-O. Monod, Frequency modulated radar: a new sensor for natural environment and mobile robotics. Ph.D. Thesis, Paris VI University, France, 1995.

[7] M.I. Skolnik, "Introduction to radar systems," in Electrical Engineering Series, McGraw-Hill International, Eds. New-York, 1980.

[8] M. Jaud, R. Rouveure, P. Faure, and M-O. Monod, "Methods for FMCW radar map georeferencing", ISPRS Journal of Photogrammetry and Remote Sensing, vol. 84, pp. 33-42, October 2013.

[9] E. Meier, U. Frei, and D. Nüesch, "Precise terrain corrrected geocoded images," in SAR Geocodong - Data and Systems, G. Schreier, Eds. Karlsruhe: Wichman, 1993, pp. 173-185.

[10] J.C. Curlander, and R. McDonough, "Synthetic aperture radar: Systems and signal processing," in Wiley Series in Remote Sensing and Image Processing, vol. V, Wiley, Eds. New York, 1991. 